\title{
Study of Spatial Pattern of County-level E-commerce and Its Influential Factors in Zhejiang Province, China
}

\author{
Zhong Hai-dong ${ }^{1}$, Yu Xin-wu ${ }^{2}$, Lv Hongbo ${ }^{1}$ and Li Ping ${ }^{3, *}$ \\ ${ }^{1}$ Logisticsand E-commerce school, Zhejiang Wanli University, Ningbo, 315100, \\ Zhejiang, China \\ ${ }^{2}$ The Information Center, Zhejiang Wanli University, Ningbo, 315100, Zhejiang, \\ China \\ ${ }^{3}$ *Correspondent author, College of Biological \& Environmental Sciences, \\ Zhejiang Wanli University, Ningbo, 315100, Zhejiang, China \\ zhonghaidong@zwu.edu.cn,ddianel@qq.com,184650587@qq.com, \\ liping_kaixin@126.com
}

\begin{abstract}
Investigation of e-commerce spatial distribution pattern and its influence factors is very important. The study plays an important role in e-commerce-related industrial spatial layout, industrial structure optimization and balanced development of a regional economy. First of all, the paper studies the basic spatial pattern of e-commerce in Zhejiang province at city scale, and then further analyzes spatial development characteristics of e-commerce and its influencing factors in the province at the county level. All the investigation is conducted using a spatial analysis tool in ArcGIS and regression analysis in SPSS. The study shows that: (1) in city scale, e-commerce development level decreases gradually from the central of Zhejiang province to the outer areas; also it decreases from the west to the east of Zhejiang province; (2) in county scale, e-commerce development level is relatively high in the middle of the counties (county-level cities) in Zhejiang province, but the overall uneven e-commerce development is very obvious, and (3) number of Internet users, local finance income and postal business income are the key factors affecting the development of e-commerce in counties in Zhejiang province, while population and rural per capita disposable income have been proved not to be.
\end{abstract}

Keywords: Zhejiang Province; County-level e-commerce; Spatial distribution; ArcGIS; SPSS

\section{Introduction}

County economy has become an important driving force of the country's economic growth in China. It undertakes industrial transfer, optimizes the economic structure, promotes the development of industrialization and urbanization, and plays an important role in aspects of absorbing rural surplus labor. In recent years, county economy has contributed $50 \%$ of China's GDP and affected nearly $70 \%$ of the population of the nation [1-2]. Although the overall level of the county economy development is currently low, it has the obvious advantage of backwardness and its development trend is good. In the future, county economy is expected to be one of the most important supporting points for urbanization and economic growth in China [3-4].

Currently, e-commerce has become one of the most important ways of transforming and upgrading the county economy in China [5]. With open, global, low cost, high efficiency and other advantages, the e-commerce industry developed quickly in China in 
the last five years. According to the China Electronic Commerce Research Center's ${ }^{1}$ statistics, China's e-commerce transaction amount exceeded 18 trillion yuan, up 36.5\% from a year earlier and there were more than 2.7 million people directly employed by ecommerce service enterprises in $2015^{2}$. At the same time, more than 20 million jobs were indirectly promoted by e-commerce, and county e-commerce played as a new growth pole.

County-level e-commerce is significant for the Zhejiang province. It is the only province with two cross-border e-commerce comprehensive pilot areas, with Broadband network covering all villages in China. There are more than 800 express delivery companies, more than 6000 service outlets located in almost all the villages and towns across the province, and nearly all village located companies are involved in e-commerce [6]. According to the latest data released by the Ali Research Institute ${ }^{3}, 41$ counties in Zhejiang province have won the honor of "the top 100 e-commerce counties in China", ranking first in total number and far ahead of the province ranked second ${ }^{4}$.

With the help of the Internet, the role of county e-commerce will be more obvious in promoting regional economic development in the future. Penetration of the Internet from big cities gradually into the county and village is now making a new challenge against the central position of metropolises. In the Internet age, the traditional concept of time and space are constantly changing, and the pattern of regional development becomes wider. With the penetration of the Internet from the big cities gradually into the counties and villages, the traditional concept of time and space are constantly changing, the pattern of regional development is more broad, and the center of the city status will be challenged $[4,7]$. In the next five to ten years, the role of e-commerce in promoting county economy and social development will be further highlighted. On this occasion, Zhejiang province should make full use of its own development advantages, summarize its development achievements, draw lessons from successful experiences at home and abroad to optimize the e-commerce related industrial spatial layout, vigorously develop the county ecommerce, and breed e-commerce as a new engine of county-level economic growth.

Based on the analysis above, the paper employs the e-commerce development index data released by the Ali Research Institute to analysis the basic spatial pattern of ecommerce in Zhejiang province at the city level. Afterward, the article puts emphasis on regional distribution pattern and its characteristics on county-level e-commerce development, and the influential factors are investigated accordingly. It is hoped that the research will provide a good reference for the e-commerce-related industry layout and development planning, etc.

\section{Data and Method}

\subsection{Data Source}

This paper focuses on the e-commerce development situation and the influential factors in 56 counties (county-level cities) in Zhejiang, including Jiande city, Fuyang city, Linan city, Tonglu county, Chunan county, Yuyao city, Cixi city, Fenghua city, Ninghai county, Xiangshan county, Ruian city, Yueqing city, Yongjia county, Dongtou county, Pingyang county, Cangnan county, Wencheng county, Taishun county, Haining city, Pinghu city, Tongxiang city, Jiashan city, Haiyan county, Changxing county, Deqing county, Anji county, Zhuji city, Shangyu city, Shengzhou city, Shaoxing county, Xinchangxian county, Lanxi city, Yiwu city, Dongyang city, Yongkang city, Wuyi county, Pujiang county, Panan county, Jiangshan city, Longyou county, Changshan county, Kaihua county,

\footnotetext{
${ }^{1} \mathrm{http}: / / \mathrm{www} .100 \mathrm{ec} . \mathrm{cn} /$

${ }^{2}$ http://www.100ec.cn/detail--6333644.html

${ }^{3} \mathrm{http}: / / \mathrm{www}$. aliresearch.com/

${ }^{4}$ http://www.aliresearch.com/blog/article/detail/id/20431.html
} 
Daishan county, Shengsi county, Linhai city, Wenling city, Yuhuan county, Tiantai county, Xianju county, Sanmen county, Longquan city, Jinyun county, Qingtian county, Yunhe county, Suichang county, Songyang county, Qingyuan county, and Jingning autonomous county. The data used in the paper can be divided into the following three categories.

(1) Basic geographic data of city and county in Zhejiang province (including area, rivers, city, county-level administrative boundaries). These data are downloaded from the national basic data and public data sharing websites.

(2) Economic and social development data of 56 counties (county-level cities) in Zhejiang province, including population, the added value of the first, second and third industries, per capita GDP, per capita disposable income, goods or throughput, express daily ticket sales at home and abroad, the postal business income, the telecom business income, broadband Internet users, mobile phone users. These data are extracted from government official statistical bulletin and statistical yearbook.

(3) E-commerce development indicators data, such as e-commerce development index (EDI), electronic retailing index (ERI), electronic buying index (EBI), of China. These data are queried from "top 100 e-commerce counties list in China" in 2014 and countylevel e-commerce development index in China ${ }^{6}$, released by the Ali Research Institute.

\subsection{Research Methods}

Motivated by the convenience of the new kind of consumption pattern, piles of articles have been conducted in e-commerce related research. Most of the studies focused on the e-commerce concept definition [8], trust issues [9-10], personalized recommendation [11], consumer behavior patterns [12], big data analysis [13], etc. E-commerce space distribution characteristics and its related influencing factor analyses belong to the category of economic geography. It is an interdisciplinary field between geography and economics, which has not formed a mature research paradigm [14-16]. In this paper, GIS (Geographic Information System) spatial analysis theory and method, more specifically ArcGIS spatial analysis tools, are employed to analyze spatial autocorrelation, gathering and hot spot of the level of e-commerce development in Zhejiang province. In addition, the multiple regression analysis method of SPSS is used to analyze the factors affecting the e-commerce development level quantitatively.

\subsubsection{Spatial Autocorrelation and Aggregation Analysis}

Moran index (Moran's I) is an important evaluation index put forward by a famous Australian statistician in 1950. It is widely used to measure a point on the mutual dependence between attribute data and other points. This tool creates a new output with Local Moran's I index, z-score, p-value, and cluster/outlier type. The z-scores and pvalues are measures of statistical significance, which tell you whether or not to reject the null hypothesis. If $\mathrm{z}$-score is less than -1.96 or greater than 1.96 , it indicates a credible spatial autocorrelation analysis result (confidence level higher than 95\%); otherwise, the calculation result is a random distribution. A z-score greater than 1.96 means data between the counted locations is collective. On the other hand, if the z-value is less than 1.96, the result is discrete. In ArcGIS, Moran's I can be calculated by the formula [17-18].

$$
I=\frac{n}{S_{0}} \frac{\sum_{i=1}^{n} \sum_{j=1}^{n} w_{i, j} z_{i} z_{j}}{\sum_{i=1}^{n} z_{i}^{2}}
$$

\footnotetext{
${ }^{5}$ http://www.aliresearch.com/blog/article/detail/id/20431.html

${ }^{6} \mathrm{http}: / /$ topic.aliresearch.com/market/aliresearch/aedi.php
} 
In the formula, $\mathrm{z}_{i}$ indicates a deviation $\left(x_{i}-\bar{X}\right)$ between observed value $\left(x_{i}\right)$ and desired value at position $i ;{ }^{w_{i, j}}$ shows a spatial relation between location $i$ and ${ }^{j} ; n$ indicates the number of all observation positions, and $\left.S_{0} S_{0}=\sum_{i=1}^{n} \sum_{j=1}^{n} w_{i, j}\right)$ shows a sum total of all the values at each observed point. ${ }^{z_{i}}$ can be calculated using the following methods:

$$
z_{i}=\frac{I-E[I]}{\sqrt{V[I]}}
$$

In formula (2), $E[I]=-\frac{1}{n-1}, V[I]=E\left[I^{2}\right]-E[I]^{2}$.

G coefficient, proposed by Getis Arthur, J.K., is an important indicator for measuring the clustering situation of data between two locations. The following formula is usually used to calculate its value [19-20]:

$$
G=\frac{\sum_{i=1}^{n} \sum_{j=1}^{n} w_{i, j} x_{i} x_{j}}{\sum_{i=1}^{n} \sum_{j=1}^{n} x_{i} x_{j}}, \forall j \neq i
$$

In formula (3) ${ }^{x_{i}}$ and ${ }^{x_{j}}$ denote the observed value of locations ${ }^{i}$ and ${ }^{j}$ respectively, and $w_{i, j}$ denotes spatial weight value between locations $i$ and ${ }^{j}$. G coefficient can also be figured out with the help of ArcGIS spatial statics toolbox; however, the calculated value is standardized. The specific standardization process is as follows:

$$
z_{G}=\frac{G-E[G]}{\sqrt{V[G]}}
$$

In formula $E[G]=\frac{G-E[G]}{\sqrt{V[G]}}$ and $V[G]=E\left[G^{2}\right]-E[G]^{2}$.

The high or low cluster possibility of the attribute values at observed places can be inferred according to the calculated $\mathrm{G}$ value.

\subsubsection{Quadrifid Graphs}

A quadrifid graph [21] is a diagnostic model that combines quantitative analysis and qualitative research approaches. It was proposed by a scholar at the Ohio State University in the study of leadership behavior related theory and can also be called a twodimensional structure surface theory.

Initially, the quadrifid graph model adopts a two-dimensional axis that forms four quadrants to represent the four types of leadership behavior (as shown in Figure 1)-high organization and considerate, low organization and considerate, high low organization and considerate, high consideration and low groups. Later, many scholars found it has a very important application value in the comprehensive analysis of the effects of two groups (or two) index. Besides, it can be applied very widely, such as in enterprise comprehensive evaluation [22], customer satisfaction evaluation [23], etc. 


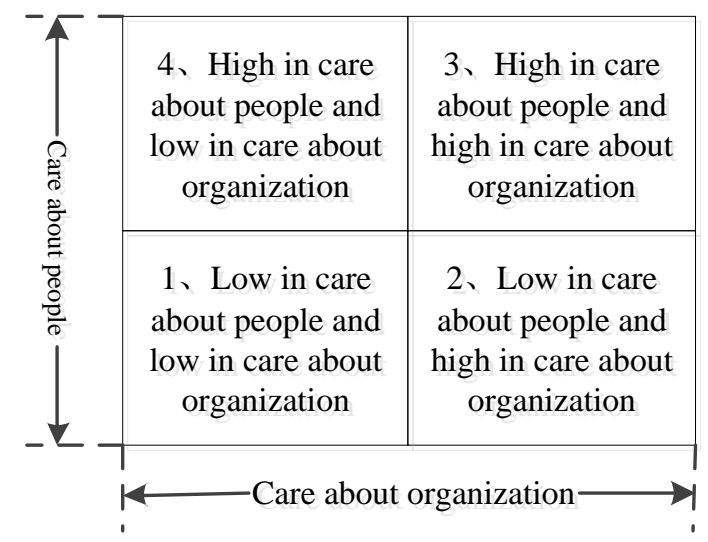

Figure 1. Quadrifid Graph Model

\section{Spatial Characteristics of County-Level E-commerce Development in Zhejiang Province}

According to "top 100 e-commerce counties list in China" in 2014 released by the Ali Research Institute, the overall e-commerce development level in Zhejiang province is higher than other provinces (municipalities with independent planning status) in China. In order to further study the spatial characteristics of e-commerce in Zhejiang province, both city scale and county scale spatial analysis are conducted.

\subsection{City Scale Spatial Analysis}

City scale spatial analysis of e-commerce in Zhejiang province indicates (as shown in Figure 2, the result is presented according to 4 categories' division method) obvious features of gradient distribution. As can be seen from Figure 2, the overall e-commerce development index in Hangzhou city and Jinhua city rank first; Huzhou city, Taizhou city and Shaoxing city rank second, and Jiaxing city, Ningbo city, Wenzhou city, Quzhou city and Lishui city rank third or fourth. Measured by EBI, Jinhua city rank first of all the cities in Zhejiang province. Measured by ERI, only Hangzhou city rank first. In addition, Quzhou city and Lishui city are the most under-developed cities in Zhejiang province measured whether by EDI, ERI or EBI. 


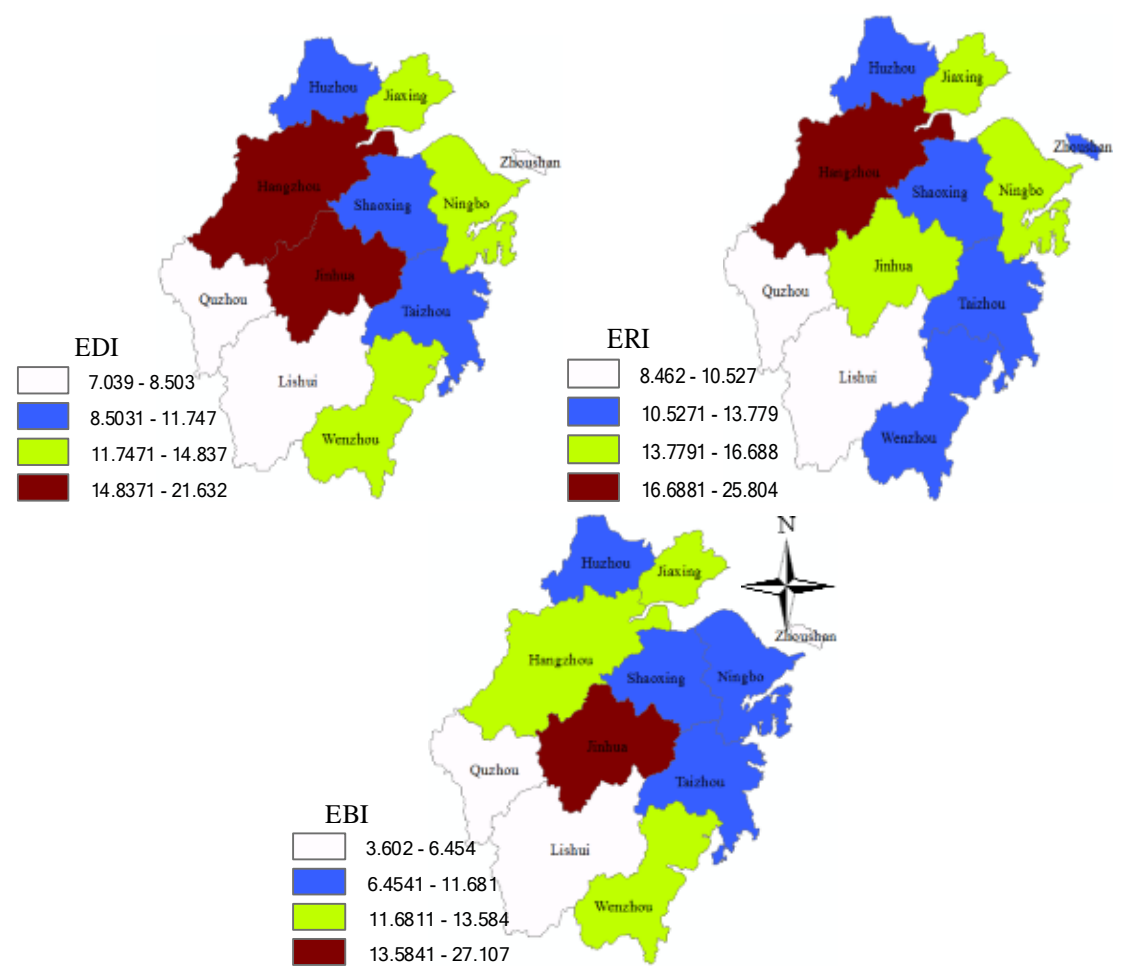

Figure 2. Spatial Distribution of E-commerce of Zhejiang Province at the City Level

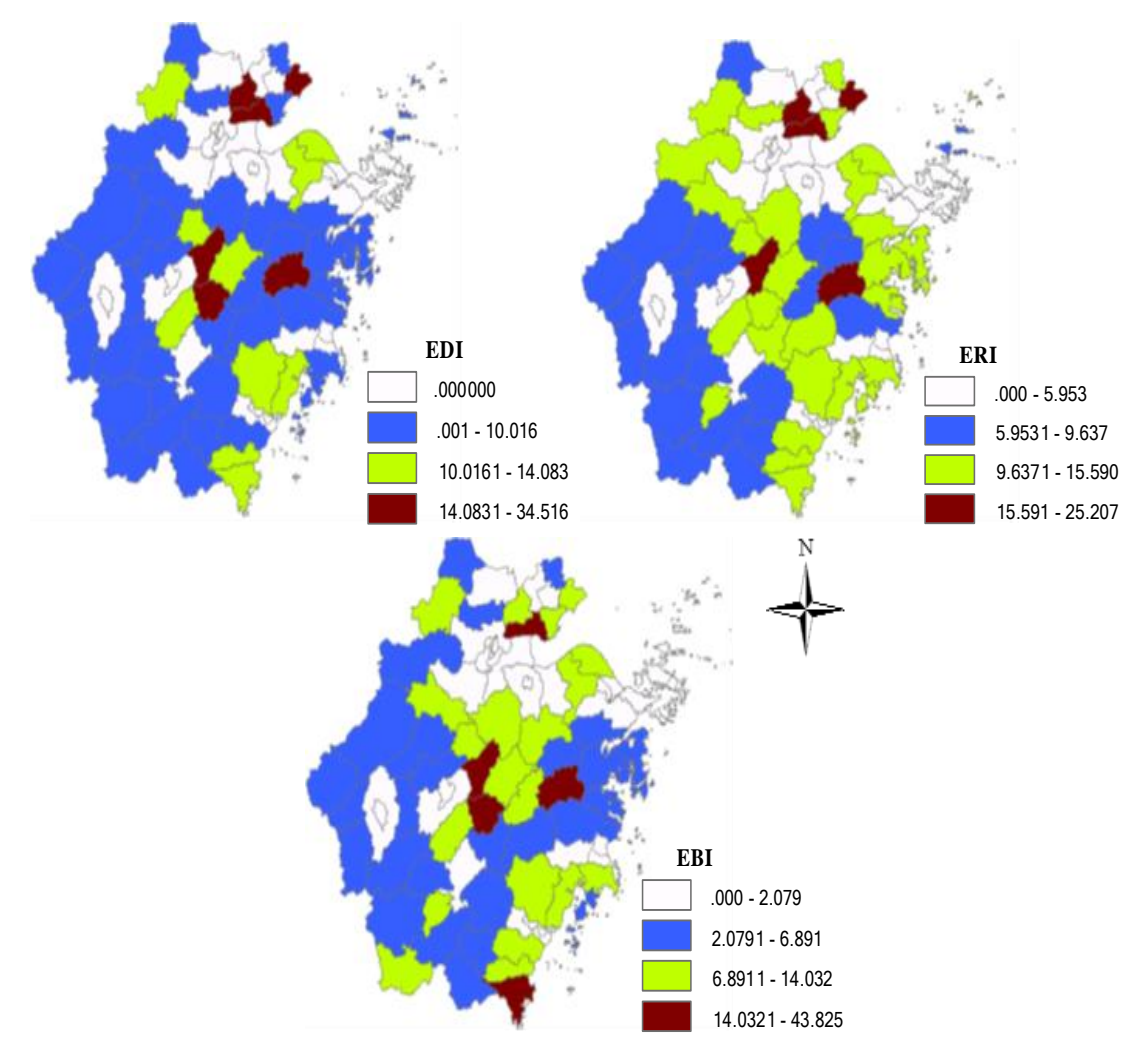

Figure 3. Spatial Distribution of E-commerce of Zhejiang Province at the County Level 


\subsection{County Scale Spatial Analysis}

In order to further study the spatial pattern of e-commerce development of the Zhejiang province from a more detailed spatial scale, we calculated the EDI, ERI and EBI in 56 counties (county-level cities). The result is shown using the geometrical interval 4-grade method (as shown in Figure 3).

At a county scale, unbalanced development of e-commerce is more prominent in Zhejiang. Measured by EDI, electronic commerce development level in Pinghu city, Haining city, Tongxiang city, Tiantai county, Yongkang city, and Yiwu city rank first; Ruian county, Yongiia county, Pingyang county, Leqing city, Cangnan county, Pujiang county, Wuyi county, Dongyang city, Cixi city, Yuyao city, Anji rank second; and the third and fourth level cities (counties) are mainly concentrated in the southwest and northeast region of Zhejiang province. Generally, there are obvious ladder-like distribution characteristics of county-level e-commerce spatial distribution in Zhejiang province.

By comparing ERI and EBI in all counties (county-level cities), it can be found that the overall e-commerce development level of counties in the central region of Zhejiang province is higher than in other counties. Spatial distribution of ERI and EDI shows an overall consistency: with the increase of the distance between the central region and the county (county-level city), e-commerce development level decreases obviously. However, spatial distribution of county-level EBI showed more diversity than that of EDI and ERI. It presents a "radial" gradient descending distribution characteristics from the central county (county-level city) to the outer of Zhejiang province and the high-level intensive distribution feature is not so obvious. In addition, counties (county-level cities) in the northwest of Zhejiang province show a high level of intensive distribution characteristic, measured by EDI, EBI and ERI. However, compared with the central region, the scope and scale of these counties are small, and the influence is limited.

\subsubsection{Development Status Analysis}

EDI, according to the Ali Research Institute, is formed by EBI and ERI, both weight $50 \%$ each, which implies that they have equal importance to EDI. To analyze county-level e-commerce development status, a quadrifid graph (as shown in Figure4), uses EBI and ERI as X-and Y-axis, respectively. In Figure 4, 56 counties (county-level cities) are divided and shown in four areas, A (high EBI, high ERI), B (low EBI, high ERI), C (low EBI, low ERI), and D (high EBI, low ERI), according to the ERI mean value 10.86 and EBI mean value 8.11. It can be found from Figure 4 that e-commerce development of 17 counties (county-level cities)-Linghai city, Suichang county, Panan county, Longquan city, Changxing county, Chunan county, Qingtian county, Jiande city, Jingning autonomous county, Shengsi county, Lanxi city, Taishun county, Changshan county, Daishan county, Longyou county, Kaihua county and Wencheng county-are in high EBI and high ERI status. E-commerce development in relatively fewer counties-Jiangshan city, Xiangshan and Songyang county-is in low EBI and high ERI status. E-commerce development in most counties, e.g. Pingyang county, Haining, Dongyang, is in low EBI and low ERI status, and they are almost distributed equally in Zhejiang province. Furthermore, high EBI and low ERI counties (county-level cities), such as Deqing county, Yuyao city and Fenghua city, are mainly located in the southeast of Zhejiang province. Overall, county-level e-commerce development of Zhejiang province is mainly concentrated in "low EBI and low ERI" and "high EBI and high ERI" status and the former is in the dominant position, which implies a wholly less developed and disparate development of county-level e-commerce in Zhejiang province. 


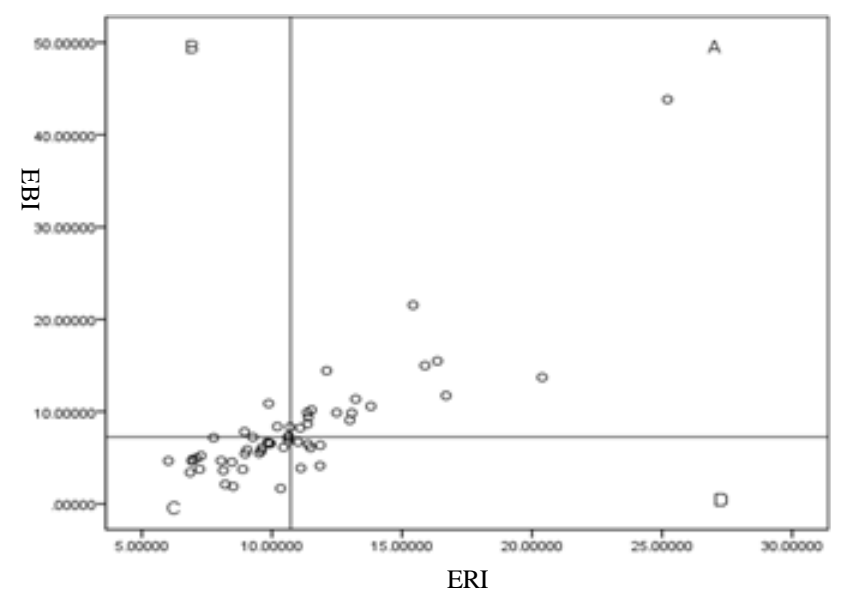

Figure 4. Quadrifid Graphs of EBI and ERI of E-commerce in the Counties of Zhejiang Province

\subsubsection{Spatial Aggregation Analysis}

Spatial aggregation characteristic of county-level e-commerce in Zhejiang province is measured by Moran's I index, which is calculated in ArcGIS 10.3.1, and the result is shown in Table 1.

Table 1. The Moran's I of E-commerce Level in Counties of Zhejiang Province

\begin{tabular}{|c|c|c|c|}
\hline Index Name & $\begin{array}{l}\text { Moran's I } \\
\text { index }\end{array}$ & $\begin{array}{l}Z \text { test } \\
\text { value }\end{array}$ & $\begin{array}{l}\text { Significance } \\
\text { level }\end{array}$ \\
\hline EDI & 0.41 & 11.02 & 0.01 \\
\hline ERI & 0.52 & 14.23 & 0.01 \\
\hline EBI & 0.34 & 9.56 & 0.01 \\
\hline
\end{tabular}

In Table 1, Z-test values of EDI, EBI and ERI are positive and all through the inspection under the 0.01 significance level, which indicates an obvious collective spatial tendency of county-level e-commerce in Zhejiang province.

To further analyze hot and cold spot of county-level e-commerce development status in Zhejiang province, the spot analysis (Getis-Ord Gi*) tools in ArcGIS are utilized to analyze hot spot of EDI, EBI and ERI in Zhejiang province (as shown in Figure 5).

As can be found in Figure 5, there are the following three characteristics: (1) hot and cold agglomeration pattern of EDI, EBI and ERI are basically identical; (2) county-level e-commerce hotspot counties, such as Yiwu city, Yongkang city, Dongyang county, etc., are concentrated in the central of Zhejiang province, and (3) county-level e-commerce cold spots, for example, Fuyang city, Changshan county, Longyou county, etc., are distributed far from hotspot counties (county-level cities). Additionally, spatial analyses of EDI, ERI and EBI indicate Cangnan county and Haiyan county hotspots, which indicates high-level county e-commerce development status in these two counties. 


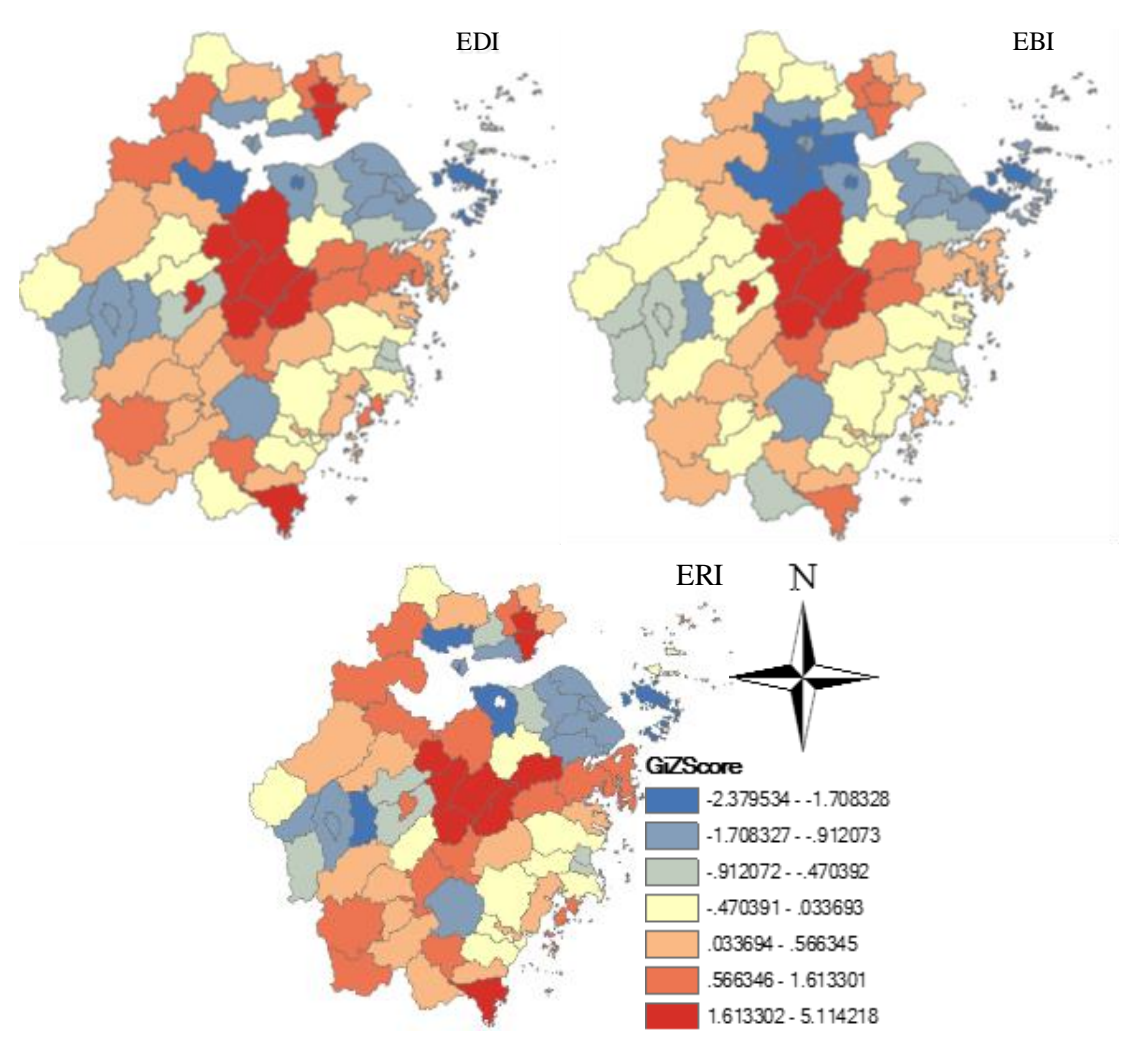

Figure 5. Getis-Ord Gi Map of E-commerce Level in Counties of Zhejiang Province

\section{Influence Factors of County-Level E-commerce Spatial Distribution in Zhejiang Province}

\subsection{Influence Factor Analysis and Model Building}

As is known to all, e-commerce development is influenced by many factors in economic and social development. To study the influence factors of county-level ecommerce spatial distribution in Zhejiang province, the research selected the three types of indexes to conduct geographically weighted regression analyses. The indexes contain: (1) social development indicators, including population (POP) and gross domestic product (GDP); (2) economic development indicators, including per capita gross domestic product (AVGGDP), local fiscal revenue (LFINCOME), local fiscal expenditure (LFEXPEND), urban per capita disposable income (CDAVGINCOME) and rural per capita disposable income (RDAVGINCOME); and (3) E-commerce development support indicators, including the number of mobile phone users (MOBILENUM), the number of Internet users (INTERNETNUM), and the postal business income (POSTALINCOME). Then the EDI, ERI and EBI of each county (county-level city) are selected as dependent variables to establish the following multiple linear regression models:

$$
\begin{aligned}
& y=a+b_{1} \text { POP }+b_{2} G D P+b_{3} \text { AVGGDP }+b_{4} \text { LFINCOME }+b_{5} \text { LFEXPEND } \\
& +b_{6} C D A V G I N C O M E+b_{7} \text { RDAVGINCOME }+b_{8} \text { MOBILENUM }+b_{9} \text { POSTALINCOME } \\
& +c_{1} E D I+c_{2} E R I+c_{3} E B I \\
& \text { In the above regression model, } \mathrm{y} \text { is the explained variable, }
\end{aligned}
$$


$b_{1}, b_{2}, b_{3}, b_{4}, b_{5}, b_{6}, b_{7}, b_{8}, b_{9}$ and $c_{1}, c_{2}, c_{3}$ are coefficients, and $a$ is a specially introduced standardizing constant value.

\subsection{Regression Results Analysis}

To investigate the internal connection between various elements that influence the development of county-level e-commerce, SPSS 19.0 is utilized to conduct a multiple regression analysis based on the multiple linear regression models above (the result is shown in Table 2).

In the three variables' regression analysis model, the average level of F-test value is 0.000. It implies a high significance of the model and a relatively high linear correlation between the dependent variable and independent variables. According to the result judgment index R2, linear fitting degree between ERI and variables is the best, and EDI rank the second best. Even the lowest interpretation degree between EBI and other dependent variables is as high as $68.6 \%$. Overall, Table 2 shows that Internet users have the most prominent influence on EDI, ERI and EBI, which indirectly confirms that it plays an important support role for the development of e-commerce.

Table 2. Estimation Results of Multivariable Linear Regression Model

\begin{tabular}{|l|c|c|c|}
\hline & EDI & EBI & ERI \\
\hline POP & $-0.481^{\mathrm{a}}$ & $-0.464^{\mathrm{a}}$ & $0.415^{\mathrm{b}}$ \\
\hline LFINCOME & 1.188 & 0.925 & -1.527 \\
\hline AVGGDP & $0.165^{\mathrm{a}}$ & $-0.109^{\mathrm{a}}$ & $0.202^{\mathrm{b}}$ \\
\hline LFEXPEND & -0.911 & -0.886 & -0.858 \\
\hline CDAVGINCOME & 0.256 & -0.354 & $0.064^{\mathrm{b}}$ \\
\hline RDAVGINCOME & -0.382 & -0.607 & $-0.043^{\mathrm{a}}$ \\
\hline MOBILENUM & $-0.00043^{\mathrm{b}}$ & 0.117 & 0.206 \\
\hline INTERNETNUM & $1.544^{\mathrm{a}}$ & $1.51^{\mathrm{a}}$ & $1.414^{\mathrm{a}}$ \\
\hline POSTALINCOME & $0.107^{\mathrm{a}}$ & $0.136^{\mathrm{a}}$ & $0.051^{\mathrm{a}}$ \\
\hline GDP & 0.532 & 0.374 & 0.785 \\
\hline $\mathrm{R}^{2}$ & 0.76 & 0.77 & 0.686 \\
\hline Adjusted $\mathrm{R}^{2}$ & 0.705 & 0.718 & 0.615 \\
\hline F value & 13.907 & 14.743 & 9.628 \\
\hline Sample quantity & 55 & 55 & 55 \\
\hline Const value & 11.849 & 12.317 & 11.0443 \\
\hline
\end{tabular}

Note: superscript a:p<0.01, b: $\mathrm{p}<0.05$

As can be seen from Table 2, spatial distribution of county-level e-commerce is remarkably influenced by LFINCOME, AVGGDP, CDAVGINCOME, INTERNETNUM, POSTALINCOME and GDP. Among these variables, INTERNETNUM is the most important influencing factor, which confirms a strong connection between Internet users and e-commerce development status. Besides, the relevancy of LFINCOME illustrates that e-commerce is an important driving force for the development of the local economy. Surprisingly, there is an obvious negative correlation between POP and county-level e-commerce development status. This may result in a great movement of the population in urban areas and does not cause a significant impact on local e-commerce development. LFINCOME is usually adopted as a major indicator for measuring the development level of a local economy, but in Table 2, the variable is an evident negative correlation between LFINCOME and county-level e-commerce development status. The reason may be that local fiscal expenditure investment in many 
industries and its leading role in the development of e-commerce is not so obvious. RDAVGINCOME is one of the important indicators for measuring rural purchasing power, but in Table 2 the variable shows a negative correlation to the level of county ecommerce development status. In addition, the impact of MOBILENUM on county ecommerce development is not so significant. This may imply the fact that mobile ecommerce development level in the counties (county-level cities) of Zhejiang province is not high.

From the point of ERI regression analysis results residents' network shopping and LFINCOME MOBILENUM, INTERNETNUM GDP and POSTALINCOME have a significantly positive correlation, but the impact of POP, AVGGDP, LFEXPEND, CDAVGINCOME and RDAVGINCOME on enterprise usage is not so significant.

EBI regression analysis results show that some variables, such as POP, AVGGDP, CDAVGINCOME, RDAVGINCOME, INTERNETNUM, MOBILENUM, GDP and POSTALINCOME have an obvious positive impact on network shopping. Moreover, LFINCOME, LFEXPEND and online development level show a significant negative correlation, which reveals that county-level e-commerce has not developed to the degree of influencing county (county-level city) fiscal revenue and expenditure.

\section{Conclusions}

In this paper, China county-level e-commerce development data, and the basic geographic data of China and economic and the social development statistical data of Zhejiang province are comprehensively used. With the help of ArcGIS and SPSS, the research mainly studies the spatial pattern and influencing factors of county-level ecommerce development characteristics in Zhejiang province. The research comes to the following conclusions:

(1) At the city level, the spatial distribution of ERI shows an obvious central city (Jinhua city) as the core and gradient descending outward characteristics, while spatial distribution of EDI and EBI interprets a prominent characteristic of gradually decreasing from west (Hangzhou city) to east.

(2) Further investigation indicates that spatial distribution of county-level e-commerce in the counties of Zhejiang is mainly dominated by "high ERI, high EBI" and "low ERI, low EBI" and there are enormous gaps between well-developed counties and underdeveloped counties. Spatial aggregation analysis of EDI, ERI and EBI show central area counties (county-level cities) (e.g., Yiwu city, Yongkang city, Dongyang county) are relatively hot spots, and e-commerce development level decreases progressively with the increase of distance from the central position.

(3) SPSS multiple regression analysis shows county e-commerce developmental level is significantly impacted by regional economic and social development factors. Among these factors, Internet users, local finance income and postal business income are the most prominent. But county (county city) population and rural per capita disposable income do not bring positive impact on county-level e-commerce development.

Spatial distribution of e-commerce development is a comprehensive reflection of regional economic factors and e-commerce related industries. The paper explores spatial pattern and the influencing factors of county-level e-commerce development characteristics in Zhejiang province. Due to many restrictions, such as availability of ecommerce development-related data, the research still has a lot of problems to be furthered. In the future, we plan to collect more real-time and accurate data, and further the research from the aspects of regional culture, policy environment and so on to analyze their impact on the development of county-level e-commerce. It is ardently anticipated that the research can provide some useful reference for the related decision-making departments while making regional e-commerce development-relevant policies. 


\section{Acknowledgement}

This work is partly supported by the Ministry of Education, Humanities and Social Sciences Search project (Grant No. 14YJC630210), the Zhejiang Public Technology Research and Application project (Grant No. 2015C33065), the "Zhijiang Youth Social Science Scholars" Special project of Zhejiang province (Grant No. SC1031611400040), the Ningbo Huimin project of science and technology (Grant No. 2016C51040), the Zhejiang Province Department of Education project (Grant No. Y201431553), the Zhejiang Commercial Economy Society project (Grant No. 2016SJYB01), the Modern Port Service Industry and Culture Research Center of the Key Research Base of Philosophy and Social Sciences of Zhejiang Province.

\section{References}

[1] J. C., Liu Rresearch review and reflection of county territory economy development pattern in China, Enterprise Economy, no. 2, (2013), pp. 154-158 (in Chinese).

[2] K. Liu, County economy electricity has huge potential [EB/OL]. http://finance.sina.com.cn/roll/201602-23/doc-ifxprucs6388165.shtml, 2016-07-23.

[3] G. B. Liu, "Sub-pole" development rule for county economy: strategies for the development of northeastern China county economy, Jilin University, Changchun, (2008)(in Chinese).

[4] C. Xu, B. Lv, T. X. Wen, New patterns of county in-situ urbanization and rural development based on ecommerce, Urban Planning International, vol. 30, no. 1, (2015), pp. 14-21 (in Chinese).

[5] C. S. Cui, S. L. Jiang, Z. H. Zhang, The Analysis of Spatial Var iability of Influencing Factor s to County Economy in Hebei Based on BGWR, Economic Geography, vol. 32, no. 2, (2012), pp. 39-45 (in Chinese).

[6] W.H. Lin, Z. H. Xu, X. F. Shen, Study on county agricultural e-commerce development countermeasure, Journal of Zhejiang Agricultural Sciences, vol. 56, no.1, (2015), pp. 127-130 (in Chinese).

[7] Y.L. Sun, Y.G. Ma, X. Dai, The development status of e-commerce of small and medium-sized cities in the process of urbanization, Journal of Inner Mong olia University for Nationalities, vol. 17, no. 4, (2011), pp. 62-64 (in Chinese).

[8] X. W. Meng, X. Hu, L. C. Wang, Y. J. Zhang, Mobile recommender systems and their applications. Ruanjian Xuebao/Journal of Software, vol. 24, no. 1, (2013), pp. 91-108 (in Chinese).

[9] Y. Zhang, J. Bian, W. Zhu, Trust fraud: A crucial challenge for China's e-commerce market, Electronic Commerce Research and Applications, vol. 12, no.5, (2013), pp. 299-308.

[10] H. D. Zhong, S. Z. Zhang, Y. L. Wang, Study on Directed Trust Graph Based Recommendation for Ecommerce System [J]. INTERNATIONAL JOURNAL OF COMPUTERS COMMUNICATIONS \& CONTROL, vol. 9, no. 4, (2014), pp. 510-523.

[11] H. L. Xu, X. Wu, X. D. Li, B.P. Yan, Comparison study of Internet recommendation system, Ruanjian Xuebao/Journal of Software, vol. 20, no. 2, (2009), pp. 350-362 (in Chinese).

[12] H. Geng, X. W. Meng, Y. C. Shi, Mobile user preference prediction method based on trust and link prediction, Journal of Electronics \& Information Technology, vol. 35, no. 12, (2013), pp. 2972-2977 (in Chinese).

[13] Y. H. Chen, L. Q. Huang, Study on the impact of big data processing in electronic commerce , Telecommunications Science, no. 3, (2013), pp. 17-21 (in Chinese).

[14] Z. W. Zhou, H. O. Zhang, W. L. Chen, Characteristics of regional distribution of online shops under C2C e-business models, Tropical Geography, vol. 31, no. 1, (2011), pp. 65-71 (in Chinese).

[15] K. B. Shi, Y. C. Yang, Q. Ren, R. Liu, Q. N. Yang, R. Zhao, Study on spatial pattern and spatial mismatch of experiential online group-buying market in China, Progress in Geography, vol. 34, no. 6, (2015), pp. 696-706 (in Chinese).

[16] Z. Y. Song, W. D. Liu, Spatial distribution and influencing factors of chinese virtual enterprises, Progress in Geography, vol. 30, no. 8, (2011), pp. 1021-1027 (in Chinese).

[17] Mitchell Andy. The ESRI Guide to GIS Analysis, Redlands, California: ESRI Press, (2005).

[18] H. D. Zhong, S. Z. Zhang, L. L. Hua, Y. Nei, Spatial pattern of C2C e-commerce online shops in China, Economic Geography, vol. 34, no. 4, (2014), pp. 91-96 (in Chinese).

[19] J.K. Ord GetisArthur, The Analysis of Spatial Association by Use of Distance Statistics, Geographical analysis, vol. 24, no. 3, (1992), pp. 189-206.

[20] S. L. Zhang, K. Zhang, Comparison between general Moran's index and Getis-Ord general G of spatial autocorrelation, Acta Scientiarum Naturalium Universitatis Sunyatseni, vol. 46, no. 4, (2007), pp. 93-97 (in Chinese)

[21] X. X. Wang, Z. Tan, On students' statisfaction with classroom teaching in universities based on quadrifid gragh model - take some universities in Jiangxi province as an example, Modern Education Science, no. 1, (2016), pp. 20-26 (in Chinese).

[22] T. Wang, Study of quarter map model on the income gap among industries, Statistical Research, vol. 32, 
no. 2, (2015), pp. 31-36 (in Chinese).

[23] L. Wu, Q. H. Zhai, An empirical analysis of power customer services based on quadrifid graph model, Journal of Nanjing Institute of Technology( Natural Science Edition), vol. 10, no. 4, (2012), pp. 57-62 (in Chinese)

\section{Authors}

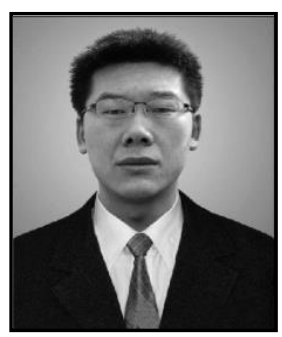

Haidong Zhong, is an associate professor in the faculty of Logistics E-commerce School in Zhejiang Wanli University. He received his B.S in computer science and technology in 2004 and his $\mathrm{PhD}$ in cartography and geography information system from East China Normal University in 2011. At present, his main research interest is in mobile e-commerce, personalized recommendation and business intelligence.

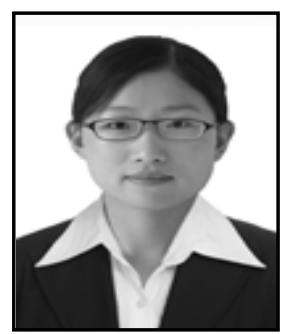

Ping Li, (born in October 1975) received his M.Sc. in 2012 from East China Normal University of China. Now he is assistant research fellow at Zhejiang Wanli University. From 2012 up to this time she is engaged in the scientific research management related work. Her current research interests include different aspects of E-commerce and Intelligent Tourism. She has (co-)authored many influential papers. 
International Journal of $u-$ and e- Service, Science and Technology Vol.10, No.4 (2017) 